\title{
The Effect of Structural Empowerment on Psychological Empowerment in Private Health Care in Biskra, Algeria
}

\author{
Borni Latifa \\ Mohamed Kheider University, Biskra, Algeria
}

\begin{abstract}
The approach of employees empowerment is one of the modern approaches in the field of human resources management. According to many studies, it has dimensions and can not be separated structural empowerment on psychological empowerment. This study aimed to recognize effect of structural empowerment in motivating psychological empowerment for employees in the private health sector in Biskra (Okba Ben Nafi Clinic, Errazi Clinic, ziadinne Clinic, Ennoor Clinic, Ibn Sina Clinic, Al-Quds clinic, Elihsen clinic, Ibn Rushd clinic, Chifa clinic, ziben clinic, and elkothben clinic). The study problem is concentrated to find answers of the following questions: what is the level of structural and psychological empowerment practiced by employees of private health sector in Biskra, how much impact structural empowerment (opportunity, support, and formal power) has on psychological empowerment (meaning, competence, self-determination, and impact) in private health sector in Biskra? To achieve the objectives of this study and answers on it questions, data were collected through questionnaire, in all (59) participants answered it. The results here, which form part of a larger study, suggest that only opportunity and formal power had significant effect on psychological empowerment, when the availability of all subscales of structural empowerment have no effect on meaning of work.
\end{abstract}

Keywords : meaning, competence, self-determination, impact, opportunity, support, formal power

\section{Introduction}

The changes and issues in enterprises environment are the bottom of many essential developments in management thinking and its application (TQM, LO, team work, KM, CSR...), because that the important of employees in the front-line is developed, specially those who have skills. The enterprises in this way obliged to give him the opportunity to conduct directly and make decision like the top manager. So, the concept of empowerment calls to abandon traditional models and philosophies "managers are thinking, the employees are doing, the good employees who are fully apply what manager says", also it does a radical change in work role.

As such, the idea of empowering employees and involving them in the enterprise management is still confident among them. Empowerment also confirms that employees at various locations are partner in making and achieving the organization's mission and goals. The health sector in Algeria is obliged to manage the diversity, because it is not in isolation from developments and changes, not only on the level of the ministry or the WHO, but also the level of thought managing and its development. This sector has taken package of reforms since 2003, which focused on many aspects, the HR is one of it; where they try to improve their

Borni Latifa, conference professor, Mohamed Kheider University, Biskra, Algeria.

Correspondence concerning this article should be addressed to Borni Latifa, Mohamed Kheider University, Department of economics science, 145 Biskra, Algeria. 
employees, financial, and material resources, communication, management of the private sector... The employees in heath sector do not do his work to the fullest. Multiple complaints from patient and visitor are on their dereliction. While the employees complained the insufficiency of physical and moral resources, which supported them to improve the sector. All that makes the problem and questions of this study; is the development of the sector's potential (resources, opportunities, power, support...) leads to psychological empowerment of workers in the health sector (meaning, competence, self-determination, and impact)? What is the level of structural and psychological empowerment practiced by employees of private health sector in Biskra? How much impact structural empowerment (opportunity, support, and formal power) has on psychological empowerment (meaning, competence, self-determination, and impact) in private health sector in Biskra?

This paper started from the following main hypothesis:

$\mathrm{H}_{0}$ : Structural empowerment (opportunity, support, and formal power) has no significant effect on psychological empowerment (meaning, competence, self-determination, and impact) in the private health sector in Biskra.

And it derives from the following sub hypothesis:

$\mathrm{H}_{0-1}$ : Structural empowerment has no significant effect on meaning of work.

$\mathrm{H}_{0-2}$ : Structural empowerment has no significant effect on competence.

$\mathrm{H}_{0-3}$ : Structural empowerment has no significant effect on self-determination.

$\mathrm{H}_{0-4}$ : Structural empowerment has no significant effect on impact.

To achieved the goals, this study is present on first level of the literature review, then methods (data collection, sample characteristics, and measures). After that, it shows the results through answered questions and tests hypotheses. Finally, the discussion, conclusion, and some recommendations are present.

\section{Literature Review}

According to Kanter, empowering structures are those that provide workers with access to information, resources, opportunity, and support. There are two systemic sources of power in organizations: formal power associated with jobs that have high visibility is essential to the organization and require independent decision-making; and informal power derived from relationships or alliances with superiors, peers, and subordinates (Miller, Goddard, \& Laschinger, 2000). Formal and informal power facilitates access to job-related empowerment structures of: (support) feedback and guidance received from superiors, peers, and subordinates... (information) the data, technical knowledge, and expertise required to function effectively in ones position... (resources) the time, materials, money, supplies, and equipment necessary to accomplish organizational goals... (and opportunity) autonomy, growth, a sense of challenge, and the chance to learn and grow (Havens \& Laschinger 1997, p. 16).

Moreover, nurses must not only perceive the work environment as empowering, the nurse must feel an inner sense of empowerment. In other words, the nurse must feel psychologically empowered, which is difined like characterized by an individual's perception that the job has meaning and that he or she is competent and able to influence outcomes and perceives a sense of autonomy (Conger \& Kanungo, 1988; Menon, 2001; Spreitzer, 1995; Thomas \& Velthouse, 1990; Zimmerman, 1995).

Psychological empowerment is an essential component of workplace empowerment, representing intrinsic task motivation, or employees' rewards that are inherent to empowering work conditions (Laschinger, Finegan, 
\& Wilk, 2009). Components of this multi-faceted construct of psychological empowerment include: meaning - a fit between job requirements and beliefs, or the value of a work objective, compared with an individual's own ideals or standards; competence - an individual's confidence or belief in their abilities to perform activities with proficiency; self-determination - sense of choice or control over ones work/autonomy and in the commencement and maintenance of work activities in the workplace; and finally, impact- the sense of being able to influence important outcomes at work (Thomas \& Velthouse, 1990). These authors stressed that the four dimensions reveal an orientation towards work reflecting the individuals desire and ability to influence his or her job and workplace (Thomas \& Velthouse, 1990).

The employees of health sector, in particular, must be fully aware of the meaning and impact on works done, also they must have competence, perceive, and believe in it; to do their work and take the appropriate decision in the appropriate time. In addition, the employees must take a personal responsibility to this work and this decision. All this characteristic must be supported by internal environment as necessary resources, and adequate opportunities, and also give discretion, make decision, and help from direct and indirect supervisors. Thus, achieving the service quality in health sector means to achieve patient satisfaction on the other. That what this study wants to confirmed or refused in Algeria health sector.

\section{Methods}

\section{Data Collection}

This study was selected clinics in Biskra (Okba Ben Nafi Clinic, Errazi Clinic, ziadinne Clinic, Ennoor Clinic, Ibn Sina Clinic, Al-Quds clinic, Elihsen clinic, Ibn Rushd clinic, Chifa clinic, ziben clinic, and elkothben clinic), which is representative of the private health sector in the wilaya. It was scanned fully, however, the response was not great, the study also refused in some clinics, 62 questionnaires out of 103 were returned (response rate of $60 \%$ ), and it have rejected three questionnaires because they are incomplete, Therefore, the study has been done on 59 questionnaire.

Table 1

Sample Characteristics $(N=59)$

\begin{tabular}{lllllll}
\hline & & Percentage $\%$ & Clinic & Percentage $\%$ & Total working years & Percentage $\%$ \\
\hline \multirow{2}{*}{ Gender } & Male & 40 & Errazi & 32.2 & Less than one year & 8.5 \\
& Female & 60 & Okba Ben Nafi & 23.7 & $1-5$ & 57.6 \\
\hline \multirow{6}{*}{ Age } & Less than 24 & 25.4 & Ennoor & 6.8 & $6-10$ & 15.3 \\
& $25-30$ & 32.2 & Ibn Sina & 8.5 & $11-15$ & 11.8 \\
& $31-36$ & 20.3 & Al-Quds & 5.1 & $16-20$ & 1.7 \\
& $37-42$ & 10.2 & Elihsen & 13.6 & more than 20 years & 5.1 \\
\\
43 years old and \\
older
\end{tabular}

\section{Sample Characteristics}

This section is mainly concerned with presenting a descriptive analysis of the sample characteristics. As Table 1 shows $40 \%$ of respondents were male and $60 \%$ were female; $25.4 \%$ of survey respondents were 24 years of age and under, $32.2 \%$ were between 25 and 30, 20.3\% were between 31 and 36, and 10.2\% were between 37 and 42 , and $11.9 \%$ were 43 or over. Finally, $8.5 \%$ of the respondents work in the private health sector since less than one year, and $57.6 \%$ between one and five years, $15.3 \%$ between six and 10 years, $11.8 \%$ between 11 to 15 years, $1.7 \%$ between 16 to 20 , and $5.1 \%$ worked longer than 20 years. 


\section{Measures}

The majority of research about empowerment of nurses and direct-care practices has focused on the exploration and testing of Kanter's in 1977 original theory of structural power in health care organizations (Tumbull, 2001). The study measured structural empowerment by the Conditions of Work Effectiveness Questionnaire (CWEQ) (Short mode) (Kristen Kiefer, 2005), originally developed by Kanter in 1977, and later adapted by chandler in 1991, with some modification to assort the Algerian society, the questionnaires have three subscales: three items for opportunity, three items for support, four items for formal power. When the study takes the model of Spritzer in determination of psychological empowerment scale; four dimensions of it were assessed: meaning (three items), competence (four items), self-determination (three items), and impact (four items).

All items were measured on a five-point Likert scale where $1=$ strongly disagree and $5=$ strongly agree. Demographic questions on gender, age, education, job mode, and work experience were also included in the questionnaire. (The questionnaire was translated form English to Arabic).

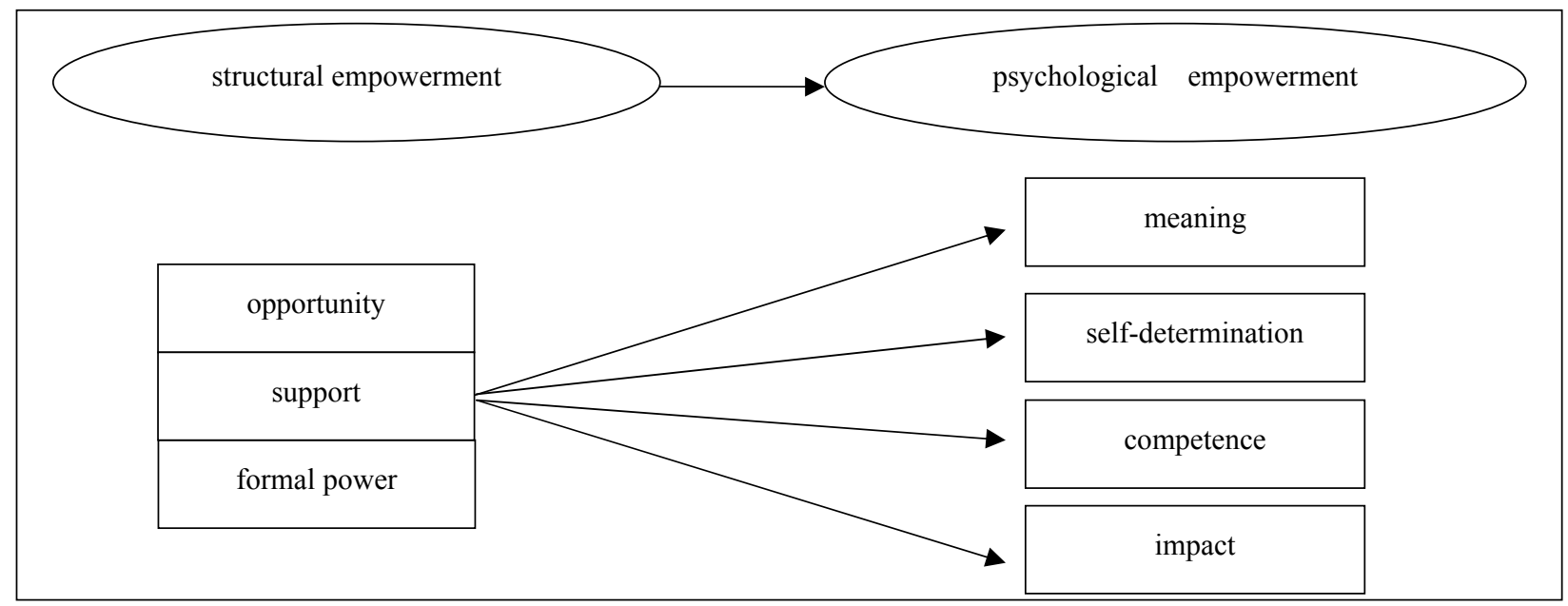

Figure 1. Proposed study model.

\section{Results}

\section{Reliability and Diagnostic of Level of Structural Empowerment With Its Dimensions and Psychological} Empowerment With Its Dimensions for Employees in Private Health Sector in Biskra

The results of Cronbach Alpha test were applied and strongly confirmed the reliability of the instrument as shown in Table 2.

The mean of overall structural empowerment reached 3.78 and the (SD) was 0.77 . This indicates that respondents perceived there was a relatively high level of structural empowerment. Among the three subscales of structural empowerment, opportunity scored the highest mean $(4.12$; $\mathrm{SD}=0.74)$, This can be explained by the nature of the work of nurses and doctors, which requires the existence of challenges at work. These challenges are considered as source of acquisition of new knowledge and skills. The second highest subscale/dimension of structural empowerment was support, with a mean of (3.96) and SD (0.89). Also, the realization of this dimension related with maximizing the profit for clinics, because that, they are obliged to provide adequate information, guidance, and criticism to employees. The lowest was formal power scoring a 
mean of (3.26), employees in this sector have no high rewards for creative activities, because managers see that creativity as part of their tasks, and they are unpaid versus any effort.

Table 2

Study Variable Descriptive

\begin{tabular}{lllll}
\hline & Items & Cronbach alpha & Moyenne & Ecart type \\
\hline Formal power & 4 & 0.868 & 3.2627 & 1.17023 \\
Support & 3 & 0.847 & 3.9605 & 0.89504 \\
Opportunity & 3 & 0.550 & 4.1186 & 0.74475 \\
SE & 10 & 0.865 & 3.7806 & 0.76647 \\
Impact & 4 & 0.797 & 3.6949 & 0.85987 \\
Meaning & 3 & 0.891 & 4.4972 & 0.69031 \\
Competence & 3 & 0.776 & 4.3178 & 0.65296 \\
Self determination & 4 & 0.811 & 4.3785 & 0.69054 \\
PE & 14 & 0.908 & 4.2221 & 0.59525
\end{tabular}

Notes. $N=59$; SE: Structural Empowerment; PE: Psychological Empowerment.

Results in Table 2 showed that the mean of overall psychological empowerment reached (4.22), with SD 0.59. This also indicates that respondents perceived there was a relatively high level of psychological empowerment. Meaning is classified in the first grade this means that employees see that their work requirements are harmonized with their beliefs that task they do have a value and nobility. According to Spreitzer's (1995) study, if employees knew the role of partial job to achieve the overall objective of the institution and feels that their job has meaning and value to the institution and the community, with utilization of many skills in work; their aware and understand that their job has meaning and value for them to grow. The mean of responses to self-determination and competence subscales were 4.37 and 4.31 , respectively. When impact takes a mean level (3.69) and ranked last between the other dimensions of psychological empowerment, this indicates that impact of employees related only to a few important things in their work, what will reduce the self motivation, which would result in their feeling of organizational alienation, and this exists frequently in the private sector, and the most of employees or all of them leave this sector once the alternative opportunities are available to them; without any sense of regret for the post of his work or its importance.

\section{Hypotheses Testing}

$\mathrm{H}_{0}$ : Structural empowerment (opportunity, support, and formal power) has no significant effect on psychological empowerment (meaning, competence, self-determination, and impact) in the private health sector in Biskra.

Table 3

The Impact of Structural Empowerment on Psychological Empowerment

\begin{tabular}{|c|c|c|c|c|c|c|c|c|c|}
\hline \multirow{2}{*}{\multicolumn{2}{|c|}{ Model }} & \multicolumn{2}{|c|}{$\begin{array}{l}\text { Unstandardized } \\
\text { coefficients }\end{array}$} & \multirow{2}{*}{$\begin{array}{l}\text { Standardized } \\
\text { coefficients } \\
\text { Beta }\end{array}$} & \multirow[t]{2}{*}{$t$} & & & & \multirow[t]{2}{*}{ Sig. } \\
\hline & & $B$ & Std. error & & & $R$ & $R$ square & $F$ & \\
\hline \multirow{2}{*}{1} & (Constant) & 2.654 & 0.335 & & 7.914 & $0.534^{\mathrm{a}}$ & 0.285 & 22.735 & 0.000 \\
\hline & SE & 0.415 & 0.087 & 0.534 & 4.768 & & & & 0.000 \\
\hline
\end{tabular}

Notes. SE: Structural Empowerment; PE: Psychological Empowerment; a. Predictors: (Constant), Structural Empowerment; $b$. Dependent Variable: Psychological Empowerment. 


\section{Regression Equation: $\mathrm{PE}=\mathbf{2 . 6 5 4}+\mathbf{0 . 4 1 5} \mathrm{SE}$}

The statistical results of the regression test, as shown in Table 3, indicate that coefficient of determination $R^{2}$ was calculated as 0.285 , which means that $28.5 \%$ of the variation in the overall psychological empowerment (all subscales together) was explained by the variation in overall structural empowerment (all subscales together).

Unstandardized coefficient $B$ was calculated as 0.415 which means that a change of 0.415 in psychological empowerment was due to a corresponding change in one unit of structural empowerment. Since calculated $F$ was 22.735 at $p \leq 0.05$, the null hypothesis is rejected. Thus, overall structural empowerment (all subscales together) as perceived by employees of private hospital in biskra had significant effect on overall psychological empowerment (all subscales together).

$\mathrm{H}_{0-1}$ : Structural empowerment has no significant effect on meaning of work.

Table 4

The Impact of Structural Empowerment on Meaning of Work

\begin{tabular}{|c|c|c|c|c|c|c|}
\hline \multirow{2}{*}{ Model } & & \multicolumn{2}{|c|}{ Unstandardized coefficients } & \multirow{2}{*}{$\begin{array}{l}\text { Standardized } \\
\text { coefficients } \\
\text { Beta }\end{array}$} & \multirow[t]{2}{*}{$t$} & \multirow{2}{*}{ Sig. } \\
\hline & & $B$ & Std. error & & & \\
\hline \multirow{4}{*}{1} & (Constant) & 3.542 & 0.530 & & 6.690 & 0.000 \\
\hline & Opportunity & 0.134 & 0.146 & 0.145 & 0.918 & 0.362 \\
\hline & Support & 0.003 & 0.120 & 0.004 & 0.029 & 0.977 \\
\hline & Formal power & 0.119 & 0.092 & 0.202 & 1.287 & 0.203 \\
\hline
\end{tabular}

Notes. $F=1.870$; Sig. $=0.145 ; R=0.304 ; R^{2}=0.093$; a. Dependent Variable: Meaning; b. Predictors: (Constant), formal power, support, and opportunity.

Results of the multiple regression test, as shown in Table 4 indicate that coefficient of determination $R^{2}$ of all structural empowerment subscales together was calculated as 0.093 , which means that $9.3 \%$ of the variation in meaning work was explained by the variation of overall structural empowerment (all subscales together). As calculated $F$ was 1.870 at $p \geq 0.05$, the hypothesis should be accepted.

$\mathrm{H}_{0-2}$ : Structural empowerment has no significant effect on competence.

Table 5

The Impact of Structural Empowerment on Competence

\begin{tabular}{|c|c|c|c|c|c|c|}
\hline \multirow{2}{*}{ Model } & & \multicolumn{2}{|c|}{ Unstandardized coefficients } & \multirow{2}{*}{$\begin{array}{l}\text { Standardized coefficients } \\
\text { Beta }\end{array}$} & & \multirow{2}{*}{ Sig. } \\
\hline & & $B$ & Std. error & & & \\
\hline \multirow{4}{*}{1} & (Constant) & 2.403 & 0.427 & & 5.627 & 0.000 \\
\hline & Opportunity & 0.368 & 0.118 & 0.419 & 3.118 & 0.003 \\
\hline & Support & -0.021 & 0.097 & -0.029 & -.221 & 0.826 \\
\hline & Formal power & 0.149 & 0.075 & 0.266 & 1.994 & 0.050 \\
\hline
\end{tabular}

Notes. $F=9.447$; Sig. $=0.000 ; R=0.583 ; R^{2}=0.340 ;$ a. Dependent Variable: competence; b. Predictors: (Constant), formal power, support, and opportunity.

Results of regression test in Table 5 showed that only opportunity and formal power had significant effect on competence $B=0.368 ; B=0.149$, respectively, but support has no significant effect. Overall structural empowerment (the three subscales together) explained $34 \%$ of the variation in competence $R^{2}=0.340$. Considering that the result of $F$ test was 9.447 at $p \leq 0.05$, the hypothesis cannot be accepted, and thus it can be said that structural empowerment has a significant effect. 
$\mathrm{H}_{0-3}$ Structural empowerment has no significant effect on self-determination.

Table 6

The Impact of Structural Empowerment on Self Determination

\begin{tabular}{|c|c|c|c|c|c|c|}
\hline \multirow{2}{*}{\multicolumn{2}{|c|}{ Model }} & \multicolumn{2}{|c|}{ Unstandardized coefficients } & \multirow{2}{*}{$\begin{array}{l}\text { Standardized coefficients } \\
\text { Beta }\end{array}$} & & \multirow{2}{*}{ Sig. } \\
\hline & & $B$ & Std. error & & & \\
\hline \multirow{4}{*}{1} & (Constant) & 2.780 & 0.487 & & 5.707 & 0.000 \\
\hline & Opportunity & 0.359 & 0.135 & 0.387 & 2.669 & 0.010 \\
\hline & Support & -0.075 & 0.111 & -0.097 & -0.678 & 0.501 \\
\hline & Formal power & 0.128 & 0.085 & 0.217 & 1.503 & 0.138 \\
\hline
\end{tabular}

Notes. $F=5.554$; Sig. $=0.002 ; R=0.482 ; R^{2}=0.232$; a. Dependent Variable: self determination; b. Predictors: (Constant), formal power, support, and opportunity.

As it appears from the results of regression test in Table 6, only opportunity had significant effect on self determination at $B=0.359$. Coefficient of determination $R^{2}$ for overall structural empowerment (all subscales together) was calculated as 0.232 , meaning that $23.2 \%$ of the variation in self determination was explained by variation in overall structural empowerment. $F$ calculated value was 5.554 at $p \leq 0.05$, so the hypothesis can not be accepted, and the study can conclude that structural empowerment has a significant effect on self determination.

$\mathrm{H}_{0-4}$ : Structural empowerment has no significant effect on impact.

Table 7

The Effect of Structural Empowerment on Impact

\begin{tabular}{|c|c|c|c|c|c|c|}
\hline \multirow{2}{*}{ Model } & & \multicolumn{2}{|c|}{ Unstandardized coefficients } & \multirow{2}{*}{$\begin{array}{l}\text { Standardized coefficients } \\
\text { Beta }\end{array}$} & & \multirow{2}{*}{ Sig. } \\
\hline & & $B$ & Std. error & & & \\
\hline \multirow{4}{*}{1} & (Constant) & 1.951 & 0.578 & & 3.375 & 0.001 \\
\hline & Opportunity & 0.103 & 0.160 & 0.089 & 0.647 & 0.520 \\
\hline & Support & 0.047 & 0.131 & 0.049 & 0.356 & 0.723 \\
\hline & Form power & 0.347 & 0.101 & 0.473 & 3.445 & 0.001 \\
\hline
\end{tabular}

Notes. $F=7.979 ;$ Sig. $=0.000 ; R=0.551 ; R^{2}=0.303$; a. Dependent Variable: impact; b. predictors: (Constant), formal power, support, and opportunity.

Results of regression test, displayed in Table 7 indicated that only formal power had significant effect on impact, the $B=0.347$. The other two subscales: opportunity and formal power had no significant effect on team communication. Considering overall structural empowerment (the three subscales together), coefficient of determination $R^{2}$ was calculated as 0.303 , which means that $30.3 \%$ of the variation in impact was explained by variation of overall structural empowerment. And as calculated $F$ was 7.979 at $p \leq 0.05$, this calls for the rejection of the hypothesis. Thus, overall structural empowerment has a significant effect on impact.

\section{Conclusion}

The main purpose of this study was to determine whether structural empowerment is related to psychological empowerment in private health sector in Biskra. It was found that employees in private health sector in Biskra, provided a relatively good level of overall structural empowerment, when its mean reached 3.78. Overall psychological empowerment scored a reasonably high level (4.22). This result is attributed to many reasons, among them: that the private health sector tries to prove its existence, and maximize profits, 
what makes him try to provide all possibilities in order to present services with the best image, as such he tries to attract qualified workers from doctors, As much as possible, to make clinic more attractive to customers (patients). As for the nurses - in most cases - remain laboring class, which must be characterized by good treatment and self-efficiency, to can stay (however, they were given another chance to work in the public sector; because of several guarantees and privileges, compared to the private sector).

Also, the workers in the private health sector feel a high degree of meaning and importance of work they do, also feel that they are competent and eligible in performing tasks. In addition, they have a self determination in their works, but their impact on it marked decline, because they are required to implement not influence or change.

There is effect to the structural empowerment on psychological empowerment in the private health sector. Overall structural empowerment was found to have a moderate positive effect on overall psychological empowerment $\left(R^{2}=0.285\right.$, Table 3$)$, this result supported prior findings about the relation between structural empowerment and psychological empowerment (Wagner, Cummings, Smith, Olson, Anderson, \& Warren, 2010; Scott Seibert, Seth Silver, \& Alan Randolph, 2004; O’Brien, 2011).

The availability of work requirements and the appropriate environment of empowerment enhance the felling of employees to do his work well; and enhance his felling for the meaning of work to him. Especially, that the sector has a great sensitivity to this dimension particularly, because the work in the health sector is noble work to all (Doctors and nurses, or administrators). For this reason, structural empowerment (all subscales together) did not show any effect on meaning of work, but it was found that structural empowerment had a positive effect on the three other subscales (competence, self determination, and impact) $\left(R^{2}=28.5 \%\right)$. Subscales of structural empowerment had deferent effect on subscales of psychological empowerment. According to the obtained results, summarized in following regression equation (C: Competence, OP: Opportunity, FP: Formal Power, SDT: Self Determination, and IM: Impact):

$$
\begin{gathered}
\mathrm{C}=2.403+0.368 \mathrm{OP}+0.149 \mathrm{FP} \\
\mathrm{SDT}=2.780+0.359 \mathrm{OP} \\
\mathrm{IM}=1.951+0.347 \mathrm{FP}
\end{gathered}
$$

The present study found that availability and access to various opportunities for employees enhance their eligibility and competence to perform the tasks assigned to them, in addition strengthen the self determination. But the absence effect on the meaning of work returns to insufficient opportunities to learn and grow, or make decisions, or even to create climate of challenge at work. As well, the support with information, aids and guidance did not affect subscales of psychological empowerment, because all of them are stemming from themselves, not from the support available.

Finally, the stepwise regression analysis was used to find the type of relation and significance between variables using Pearson's correlation coefficient found this regression equation between psychological empowerment and the tow subscales of structural empowerment (opportunity and formal power), when support is removed from the model.

$$
\mathrm{PE}=2.652+0.236 \mathrm{OP}+0.183 \mathrm{FP}
$$

\section{Recommendations}

According to the results obtained, and some interviews with employees in the private health sector in Biskra, the study recommended : 
- Reconsidering the incentives, rewards, and wages system to reinforce the structural empowerment (support) in private health sector.

- The development of system upgrade or system for increases the wage according to qualifications and work experience.

- The availability of sufficient autonomy to make appropriate decisions, train employees, and give them enough time to learn and grow.

- Disseminating empowerment cultural among employees and manager.

- Finally, this study is one of many studies, which open-minded to search private health sector problems for more.

\section{References}

Conger, J. A., \& Kanungo, R. N. (1988). The empowerment process: Integrating theory and practice. Academy of Management Review, 13(3), 471-482.

Havens, D. S., \& Laschinger, H. S. (1997). Creating the environment to support shared governance; Kanters theory of power in organizations. Journal of Shared Governace, 3(1), 15-23.

Kristen Kiefer, M. (2005). Measuring long-term care work, a guide to selected instruments to examine direct care worker experiences and outcomes, the US Department of Health and Human Services. US Department of Labor, pp. 8-10.

Laschinger, H. K. S., Finegan, J., \& Wilk, P. (2009). Context matters. The impact of unit leadership and empowerment on nurses organizational commitment. Journal of Nursing Administration, 39(5), 228-235.

Menon, S. T. (2001). Employee empowerment: An integrative psychological approach. Applied Psychology: An International Review, 50(1), 153-180.

Miller, P. A., Goddard, P., \& Laschinger, H. K. S. (2000). Evaluating physical therapists perception of empowerment using Kanters theory of structural power in organizations. Physical Therapy, 81(12), 1880-1888.

O'Brien, J. L. (2011). Relationships among structural empowerment, psychological empowerment, and burnout in registered staff nurses working in outpatient dialysis centers. Nephrology Nursing Journal, 38(6), 475-481.

Scott Seibert, E., Seth Silver, R., \& Alan Randolph, W. (2004). Taking empowerment to the next level: A multiple-level model of empowerment, performance, and satisfaction. Academy of Management Journal, 47(3), 332-349.

Spreitzer, G. (1995). Psychological empowerment in the workplace: Dimensions, measurement and validation. Academy of Management Journal, 38(5), 1442-1465.

Thomas, K. W., \& Velthouse, B. A. (1990). Cognitive elements of empowerment: An interpretive model of empowerment in leadership. Academy of Management Review, 15, 666-681.

Tumbull, A. (2001). Ernpowerment and autonomy among continuing care nurses/residents (A thesis submitted to the Faculty of Graduate Studies and Research in partial fulfillment of the requirements for the degree of Master of Nursing), Edmonton, Alberta, pp. 11-13.

Wagner, J. I. J., Cummings, G., Smith, D. L., Olson, J., Anderson, L., \& Warren, S. (2010). The relationship between structural empowerment and psychological empowerment for nurses: A systematic review. Journal of Nursing Management, 18, 448-462.

Zimmerman, M. A. (1995). Psychological empowerment: Issues and illustrations. Journal of Community Psychology, 23(5), 581-599. 